\title{
Penegakan Hukum Pidana Terhadap Suporter Sepak Bola Yang Melakukan Penganiayaan
}

\author{
Zaen Ghufron Munazal ${ }^{1}$, Johny Krisnan ${ }^{2}$, Basri ${ }^{3}$ Yulia Kurniaty ${ }^{4 *}$ \\ ${ }^{1}$ Fakultas Hukum/Unimma, Indonesia \\ ${ }^{2}$ Fakultas Hukum/Unimma, Indonesia \\ ${ }^{3}$ Fakultas Hukum/Unimma, Indonesia \\ ${ }^{4}$ Fakultas Hukum/Unimma, Indonesia \\ *Corresponding Author:yuliakurniaty@ummgl.ac.id
}

\begin{tabular}{|c|c|}
\hline Histori Artikel & Abstrak \\
\hline $\begin{array}{l}\text { Masuk: } 24 \text { Feb } 2021 \\
\text { Review: } 24 \text { Feb } 2021 \\
\text { Diterima: } 4 \text { Mei } 2021 \\
\text { Terbit: } 5 \text { Mei } 2021\end{array}$ & $\begin{array}{l}\text { Tindak pidana penganiayaan yang dilakukan oleh suporter } \\
\text { sepakbola perlu mendapat perhatian khusus mengingat } \\
\text { konsekuensi penganiayaan yang dilakukan oleh suporter } \\
\text { sepakbola dapat membunuh nyawa seseorang. Penelitian ini } \\
\text { bertujuan untuk mengetahui bagaimana proses penegakan } \\
\text { hukum terhadap suporter sepak bola yang melakukan } \\
\text { pelecehan dan cara mengatasinya. Metode penelitian yang } \\
\text { digunakan adalah kombinasi antara empiris dan normatif } \\
\text { dengan pendekatan kasus penganiayaan yang dilakukan oleh } \\
\text { suporter sepak bola dan pendekatan hukum (KUH Perdata } \\
\text { Indonesia). Data diperoleh dengan melakukan wawancara dan } \\
\text { studi pustaka. Hasil penelitian menunjukkan bahwa penegakan } \\
\text { hukum terhadap suporter sepak bola yang melakukan } \\
\text { penganiayaan dilakukan dengan cara represif yaitu melakukan } \\
\text { penyidikan dan penyidikan terhadap tersangka untuk } \\
\text { kemudian dituangkan dalam Berita Acara Penyidikan untuk } \\
\text { dilimpahkan ke Kejaksaan. Adapun langkah-langkah } \\
\text { penanggulangan agar suporter sepak bola tidak melakukan } \\
\text { tindak pidana melalui upaya preventif (pencegahan), antara } \\
\text { lain sosialisasi secara terus menerus kepada komunitassuporter } \\
\text { sepak bola agar ada ketertiban hukum, koordinasi dengan } \\
\text { berbagai pihak sebelum pertandingan dimulai dan } \\
\text { memberikan pengamanan selama pertandingan berlangsung. } \\
\text { Kata Kunci : Tindak Pidana; Penganiayaan; Suporter }\end{array}$ \\
\hline Article's History & Abstract \\
\hline
\end{tabular}




\section{Ahmad Dahlan Legal Perspective}

Received: 24 Feb 2021

Reviewed: 24 Feb 2021

Accepted: 4 Mei 2021

Published: 5 Mei 2021
The criminal act of persecution committed by football supporters needs special attention considering that the consequences of persecution committed by football supporters can kill someone's life. This study aims to find out how the law enforcement process against football supporters who commit abuse and how to overcome it. The research method used is a combination of empirical and normative with the approach of cases of persecution carried out by football supporters and the legal approach (Code Civil Law Indonesia). Data obtained by conducting interviews and literature study. The results show that law enforcement against football supporters who commit persecution is by means of repressive measures, namely conducting investigations and investigations against suspects to then be stated in the Minutes of Investigation to be transferred to the Prosecutor's Office. As for countermeasures so that football supporters do not commit criminal acts through preventive (prevention) efforts, including continuous socialization to the football supporter community to have legal order, coordination with various parties before the match begins and provide security while the match is in progress.

Keywords: Criminal act; Persecution; Supporters

All articles are published online in http://journal2.uad.ac.id/index.php/adlp/

Pendahuluan

Sepak bola merupakan cabang olahraga yang paling banyak digemari dan paling populer di dunia, begitu pula di Indonesia (Welianto, 2020). Hal ini terlihat dari banyaknya jumlah penonton setiap pertandingan yang digelar, baik itu pertandingan Timnas (Tim Nasional) maupun klub-klub lokal daerah (Setiawan, 2020). Induk organisasi sepak bola di Indonesia adalah PSSI (Persatuan Sepak Bola Seluruh Indonesia) yang berdiri pada tanggal 19 April 1930 di Yogyakarta. Sepak bola tidak bisa dipisahkan dari suporter yang menjadi pemain ke duabelas untuk membangkitkan semangat bertanding klub yang didukungnya.

Hampir semua suporter klub disetiap daerah klub sepak bola tersebut berasal memiliki yel-yel atau chant yang sengaja diciptakan sendiri dan disesuaikan dengan bahasa dan budaya di daerahnya (Nugroho, 2019). Persaingan untuk menjadi suporter terbaik dan bersifat positif mendapat dukungan dari pihak klub dan pihak penyelenggara kompetisi. Oleh karena itu, selalu ada pemilihan suporter terbaik dan berhak atas hadiah yang diberikan oleh penyelenggara kompetisi. Dewasa ini, perilaku suporter sepak bola menunjukkan sikap fanatisme yang berlebihan dan sangat memprihatinkan (Indria Hapsari \& Wibowo, 2015). Masyarakat umum yang biasanya datang ke stadion secara langsung untuk mengisi waktu luang dan sekedar mencari hiburan sekaligus mendukung tim kebanggaanya kini lebih memilih 


\section{Ahmad Dahlan
Legal Perspective}

menonton dirumah melalui televisi ataupun media streaming untuk menghindari hal-hal yang tidak diinginkan (Widiyarti, 2018).

Perilaku buruk suporter sepak bola benar-benar berdampak kepada masyarakat dengan menyisakan rasa takut dan cemas masyarakat yang kemudian memunculkan stigma terhadap mereka (Alghaffar, 2017). Begitu banyak korban yang sudah berjatuhan akibat ulah suporter sepak bola tersebut. Bahkan masyarakat yang tidak mengetahui rivalitas atau permusuhan antar suporter bisa saja menjadi sasaran kekerasan atau penganiayaan yang dilakukan oleh para suporter karena rivalitas yang ada di Indonesia itu tidak hanya berlaku ketika pertandingan tersebut berlangsung, tetapi rivalitas tetap mengikuti dimana dan kapanpun mereka akan dipertemukan (Putri, 2018)(Moch. Ian Brilian Assyaumin, Yunus, \& Raharjo, 2017)(Moch. Ian Brilian Assyaumin, Yunus, \& Raharjo, 2017)(Moch. Ian Brilian Assyaumin, Yunus, \& Raharjo, 2017)(Moch. Ian Brilian Assyaumin, Yunus, \& Raharjo, 2017). Sebagai contoh kasus penganiayaan dan pengeroyokan yang terjadi pada 23 Juli 2017 yang dilakukan oleh suporter PSS Sleman yaitu Brigata Curva Sud kepada Nur Ananda, warga Desa Madyocondro, Kecamatan Secang, Kabupaten Magelang dan tiga korban lain yang merupakan warga Kabupaten Temanggung(Suyitno, 2017).

Beragam perspektif kajian terhadap perilaku suporter sepak bola dari sisi psikologis(Agriawan, 2016), kriminologi (Hanip Zaenal Mutaqin, 2017) dan antropologi(Moch. Ian Brilian Assyaumin et al., 2017), mendorong penulis untuk menelaah dari sudut pandang berbeda yakni sanksi hukum pidana bagi suporter sepakbola yang melakukan penganiayaan serta upaya pencegahannya.

Metodologi

Metode penelitian yang di gunakan adalah penelitian empiris, dikarenakan data primer diperoleh dengan teknik wawancara terhadap informan yaitu anggota Kepolisian Polres Temanggung yang pernah menangani kasus penganiayaan yang dilakukan oleh suporter sepak bola. Uji validitas data dilakukan dengan cara triangulasi data terhadap dasar hukum yang melarang perbuatan penganiayaan. Tahap akhir yaitu melakukan analisis data dengan cara deskriptif kualitatif, sehingga diperoleh penjelasan apa sanksi hukum bagi suporter sepakbola yang melakukan penganiayaan dan upaya hukum yang dilakukan Polisi untuk mencegah terjadinya kejahatan yang sering timbul bersamaan dengan diselenggarakannya pertandingan sepak bola.

Hasil and Analisis 


\section{Ahmad Dahlan \\ Legal Perspective}

Volume 01, Issue 01, 2021, pp. 59-66

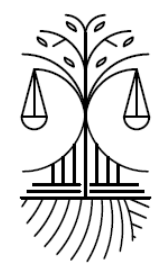

A. Penegakan Hukum Pidana Terhadap Suporter Sepak Bola Yang Melakukan Penganiayaan

Tindak pindak pidana penganiayaan yang terjadi di wilayah hukum Polres Temanggung oleh suporter sepak bola pada tanggal 23 Juli 2017 yang dilakukan oleh suporter PSS Sleman (Brigata Curva Sud) menjadikan duka yang mendalam dan menambah catatan buruk sepak bola Indonesia. Peristiwa tersebut menyebabkan korban Nur Ananda meninggal dunia dan korban Marga Damar Sabyoto mengalami luka. Aparat penegak hukum dalam hal ini Polres Temanggung mengambil tindakan tegas dan bergerak cepat untuk menangani kasus tersebut dengan menerjunkan Unit IV Reskrim Polres Temanggung mendatangi lokasi kejadian dan melakukan pengejaran terhadap pelaku penganiayaan. Di lokasi kejadian Polisi mengumpulkan barang bukti dan keterangan saksi. Selain itu juga melakukan koordinasi dengan Polsek Magelang Utara yang pada saat itu juga melakukan pengamanan wilayah yang dilewati rombongan suporter PSS Sleman, yang berhasil luput dari pengejaran Tim Reskrim Polres Temanggung. Berdasarkan wawancara dengan Purbo Triwiyoso, S.H., anggota Unit IV Reskrim Tindak Pidana Tertentu Polres Temanggung, bahwa tidak ada kejahatan yang sempurna dan selalu ada celah untuk ditemukan bukti dan fakta dari kelamahan perencanaan kejahatan.

Tindak pidana yang dilakukan oleh suporter sepak bola dapat dikenai sanksi pidana. Beberapa pasal KUHP yang bisa dikenakan kepada suporter sepak bola yang berperilaku anarkis, antara lain :

1. Pasal 170 KUHP : kejahatan terhadap ketertiban umum

2. Pasal 187 KUHP : kejahatan membahayakan ketertiban umum bagi orang atau barang

3. Pasal $351 \mathrm{KUHP}$ : penganiayaan

4. Pasal $352 \mathrm{KUHP}$ : penganiayaan ringan

5. Pasal $354 \mathrm{KUHP}$ : penganiayaan berat

6. Pasal 406 jo 407 : menghancurkan dan merusak barang milik KUHP orang lain

7. Pasal 408 jo 409 : menghancurkan bangunan sarana dan KUHP keperluan umum

Upaya represif yang dilakukan Polres Temanggung untuk menyelesaikan dan menanggulangi suatu peristiwa yang telah terjadi di lingkungan sepak bola dilakukan setelah upaya pencegahan (preventif) sudah tidak bisa diterapkan. Kebijakan ini diambil sebagai respon atas perilaku masyarakat yang tidak mematuhi himbauan untuk patuh pada aturan (Philippe Nonet, 2018). Terhadap suporter sepak bolayang 


\section{Ahmad Dahlan}

Legal Perspective

Volume 01, Issue 01, 2021, pp. 59-66

melakukan penganiayaan yang mengakibatkan satu orang korban meningga dan satu orang luka, Polres Temanggung melakukan upaya penegakkan hukum sesuai hukum acara pidana, yakni melakukan penyelidikan dan penyidikan. Proses ini untuk menentukan tersangka, menemukan barang bukti dan mengidentifikasi saksi-saksi yang keterangannya berguna dalam membuat terang akan terjadinya tindak pidana.

Dasar hukum yang digunakan untuk meminta pertanggungjawaban pelaku adalah Pasal 170 KUHP dan pasal 351 KUHP, dituangkan dalam Berita Acara Pemeriksaan (BAP). Berkas BAP yang telah lengkap dengan bukti yang menyertainya selanjutnya diserahkan ke Kejaksaan untuk menjalani proses Sistem Peradilan Pidana.

\section{B. Upaya Strategis Menekan Tindak Pidana oleh Suporter Sepak Bola}

Upaya preventif adalah suatu tindakan pengendalian sosial yang dilakukan untuk dapat mencegah atau juga mengurangi kemungkinan hal-hal yang tidak diinginkan. Aparat kepolisian sebagai aparat Negara yang bertanggungjawab atas keamanan dalam negeri yang berfungsi di bidang pemeliharaan keamanan dan ketertiban masyarakat, penegakan hukum, perlindungan, pengayoman dan pelayanan kepada masyarakat (Sekretaris Negara RI, 2002). Upaya pencegahan sangat penting karena tindak pidana yang dilakukan suporter sepak bola bukan sekedar melanggar aturan hukum, tetapi juga meresahkan masyarakat. Beberapa upaya yang dilakukan Polres Temanggung sebagai aparat penegak hukum dalam upaya pencegahan terjadinya tindak pidana oleh suporter sepak bola dan terciptanya kondusifitas di lingkungan sepak bola, yaitu :

a. Menyusun Rencana Pengamanan

Dalam penyusunan rencana pengamanan (renpam) kegaiatan sepak bola, Polres Temanggung bekerjasama dengan TNI, Satpol PP, Panitia Pelaksana (panpel), serta ASKAB PSSI Temanggung sehingga pengamanan dalam kegiatan sepak bola dapat berjalan dengan maksimal dan tidak terjadi hal-hal yang tidak dikehendaki. Aparat penegak hukum juga mempertemukan ketua kedua belah pihak suporter sebelum pertandingan untuk memberikan arahan agar pertandingan dapat berjalan dengan lancar, aman, dan kondusif.

b. Pengamanan Saat Pertandingan Berlangsung

Pengamanan di sekitar stadion juga diterapkan sebagai upaya pencegahan terhadap suporter sepak bola. Polres Temanggung mengambil langkahlangkah pengamanan dengan melibatkan fungsi operasional kepolisian, yaitu: 


\section{Ahmad Dahlan \\ Legal Perspective}

Volume 01, Issue 01, 2021, pp. 59-66

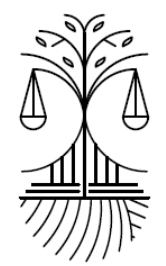

1) Fungsi Samapta, yaitu dengan melakukan patroli dan penjagaan pada saat pertandingan berlangsung;

2) Fungsi Lalu Lintas, yaitu melakukan penertiban dan keamanan pengendara di sekitar stadion atau terhadap para suporter yang akan datang ke stadion;

3) Fungsi Bina Mitra, yaitu dengan melakukan pendekatanpendekatan terhadap suporter sepak bola dan memberikan sosialisasi kepada suporter sepak bola;

4) Fungsi Intelejen, yaitu aparat penegak hukum yang bertugas mengumpulkan informasi-informasi yang berkaitan dengan jalannya pertandingan dan memberikan laporan informasi kepada fungsi yang berkaitan jika terdapat ancaman faktual yang bisa menyebabkan kerusuhan antar suporter sepak bola;

5) Fungsi Reskrim, yaitu aparat penegak hukum yang bertugas menyelenggarakan kegiatan penyelidikan dan penyidikan terhadap dugaan tindak pidana yang dilakukan oleh suporter sepak bola.

Dalam upaya yang dilakukan tersebut, sudah ditentukan juga penempatan personil berdasarkan fungsi operasional kepolisian dan sesuai dalam rencana pengamanan.

c. Melakukan Sosialisasi

Aparat penegak hukum dalam melakukan upaya-upaya pencegahan terhadap hal-hal yang tidak diinginkan dan membangun kesadaran hukum suporter sepak bola yaitu dengan melakukan sosialisasi agar terbangun sikap budaya tertib hukum (Abdul Manan, 2018). Untuk menjalin hubungan yang baik dan menciptakan sinergi positif dengan para suporter sepak bola, Polres Temanggung melakukan pendekatan-pendekatan dengan selalu menghadiri setiap acara yang diadakan oleh suporter di wilayah Temanggung sehingga dalam memberikan pemahaman dan penyadaran kepada kelompok suporter untuk mematuhi aturan hukum lebih maksimal. Sosialisasi yang sudah dilakukan Polres Temanggung terhadap suporter sepak bola diharapkan menghasilkan suporter sepak bola yang lebih bermartabat sebagai refleksi atas kepatuhan pada moralitas hukum (Prasetyo, 2015) sehingga tidak melakukan tindakan yang justru merugikan dirinya sendiri, klub yang didukung, serta masyarakat umum pecinta sepak bola.

Kesimpulan

Penegakan hukum pidana yang dilakukan Polres Temanggung terhadap suporter sepak bola yang melakukan penganiayaan adalah menerapkan proses sesuai Sistem Peradilan Pidana dengan melakukan penyelidikan dan penyidikan yang 
hasilnya dituangkan dalam Berita Acara Pemeriksaan dan selnajutnya diserahkan ke Kejaksaan untuk proses Penuntutann.

Upaya pencegahan agar tidak terjadi perilaku anarkhis oleh suporter sepakbola, Polres Temanggung melakukan sosialisasi kontinyu pentingnya menjaga ketertiban sebagai suporter sepakbola Indonesia yang bermartabat, koordinasi pihakpihak terkait sebelum pertandingan berlangsung, dan melakukan pengamanan pada saat pertandingan sedang berlangsung.

\section{Referensi}

Abdul Manan. (2018). Aspek-Aspek Pengubah Hukum. Jakarta: Kencana.

Agriawan, D. (2016). ) Hubungan Fanatisme dengan Perilaku Agresi Suporter Sepak Bola. Universitas Muhammadiyah Malang. Retrieved from http://eprints.umm.ac.id/34348/

Alghaffar, R. L. (2017). Perilaku Agresif Pada Suporter Sepakbola. Universitas Muhammadiyah Surakarta. Retrieved from http://eprints.ums.ac.id/48920/1/02. NASKAH PUBLIKASI.pdf

Hanip Zaenal Mutaqin. (2017). Tinjauan Yuridis Kriminologis Terhadap 'Hooliganisme' Oleh Massa Suporter Sepakbola Dihubungkan Dengan Pasal 170 Kitab UndangUndang Hukum Pidana. Universitas Pasundan. Retrieved from http://repository.unpas.ac.id/33970/

Indria Hapsari, \& Wibowo, I. (2015). Fanatisme Dan Agresivitas Suporter Klub Sepak Bola. Jurnal Psikologi, 8(1). Retrieved from https://ejournal.gunadarma.ac.id/index.php/psiko/article/view/1291

Moch. Ian Brilian Assyaumin, Yunus, M., \& Raharjo, S. (2017). Fanatisme Suporter Sepakbola Ditinjau Dari Aspek Sosio-Antropologis (Studi Kasus Aremania Malang). Jurnal Sport Science, 7(1). Retrieved from http://journal2.um.ac.id/index.php/sport-science/article/view/5283

Nugroho, F. T. (2019). Lirik Anthem 8 Klub Liga Indonesia, Penuh Makna. Www.Bola.Com. Retrieved from https://www.bola.com/indonesia/read/4130034/lirik-anthem-8-klub-ligaindonesia-penuh-makna

Philippe Nonet, P. S. (2018). Hukum Responsif (v). Bandung: Nusa Media.

Prasetyo, T. (2015). Keadilan Bermartabat Perspektif Teori Hukum. Bandung: Nusa Media.

Putri, A. N. K. (2018). Suporter Anarkis, Tindakan Salah Kaprah Raih Identitas 


\section{Ahmad Dahlan \\ Legal Perspective}

Volume 01, Issue 01, 2021, pp. 59-66

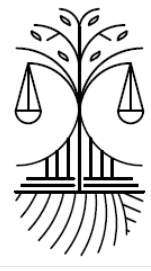

Massa

Ayobandung.Com.

Retrieved

from

https://ayobandung.com/read/2018/09/27/38592/suporter-anarkistindakan-salah-kaprah-raih-identitas-massa

Sekretaris Negara RI. Undang-Undang Nomor 2 Tahun 2002 tentang Kepolisian Republik Indonesia (2002).

Setiawan, D. (2020). Sepak Bola Tanpa Penonton Bak Salad Tanpa Rasa, Menurut Pelatih Porto. Www.Tribunnews.Com. Retrieved from https://www.tribunnews.com/superskor/2020/06/03/sepak-bola-tanpapenonton-bak-salad-tanpa-rasa-menurut-pelatih-porto?page $=$ all

Suyitno, H. (2017). Polisi rekonstruksi penganiayaan oleh suporter PSS Sleman. Www.Antaranews.Com. Retrieved from https://www.antaranews.com/berita/648180/polisi-rekonstruksipenganiayaan-oleh-suporter-pss-sleman

Welianto, A. (2020). Alasan Sepak Bola Menjadi Olahraga Populer di Dunia. Www.Kompas.Com. Retrieved from https://www.kompas.com/skola/read/2020/09/09/080000069/alasan-sepakbola-menjadi-olahraga-populer-di-dunia

Widiyarti, Y. (2018). Lebih Sehat Mana, Nonton Bola di Stadion atau Lewat Televisi? Cantik.Tempo.Co. Retrieved from https://cantik.tempo.co/read/1104720/lebih-sehat-mana-nonton-bola-distadion-atau-lewat-televisi 